\title{
THE DUAL OF THE MULTIPLIER ALGEBRA OF PEDERSEN'S IDEAL
}

\author{
KELLY MCKENNON \\ Department of Pure and Applied Mathematics \\ Washington State University \\ Pullman, Washington 99164 \\ (Received November 24, 1980)
}

ABSTRACT. It is shown that the dual of the multiplier algebra of Pederson's ideal is not always spanned by its positive elements.

KEY WORDS AND PHRASES. Multiplier algebra, Pederson's ideal. 1980 MATHEMATICS SUBJECT CLASSIFICATION CODE. Primary $46 L 05$.

1. INTRODUCTION.

In [1] Lazar and Taylor study the multiplier algebra $\Gamma(K)$ of Pedersen's minimal dense ideal $K$ of a $C^{*}$-algebra $A$. Equipped with its canonical strict topology, $\Gamma(K)$ is a locally convex space, and Lazar and Taylor have demonstrated that the dual $\Gamma(K)^{\prime}$ can be identified with the set of all linear functionals $\mathrm{A} \cdot \mathrm{F}+\mathrm{G} \cdot \mathrm{A}$ where $\mathrm{A} \in K^{+}$and F, $G \in A^{\prime}([1] 6.1)$. They have also shown that, under this identification each positive element of $\Gamma(K)^{\prime}$ is of the form $\mathrm{A}^{*} \cdot \mathrm{F} \cdot \mathrm{A}$ for some $\mathrm{A} \in K$ and $\mathrm{F} \in A^{\prime}([1] 6.5)$. This note answers negatively their question, whether or not $\Gamma(K)^{\prime}$ is the span of its positive elements.

2. MAIN RESULTS.

Let $\mathrm{H}$ denote the Hilbert space $l_{2}(\mathbf{z}),<,>$ its inner product, and $\left\{b_{n}\right\}_{n} \in \mathbf{z}$ its canonical Hilbert basis. For vectors $v, w \in H$, let $v \otimes w^{*}$ denote the linear operator sending each $x \in H$ to $\left\langle x, w>v\right.$. Denote by $\left(B, *,\|\|_{B}\right)$ the $C *-a l g e b r a$ of all bounded 
linear transformations of $\mathrm{H}$. The identity transformation I has a decomposition $\mathrm{P}+\mathrm{Q}$ where $\mathrm{P}$ is the orthogonal projection of $\mathrm{H}$ onto $l_{2}(\mathbf{N})$ and $Q$ the orthogonal projection onto $\ell_{2}(Z / N)$.

Let $A$ be the $C^{*}$-algebra of all bounded sequences $A \mid \mathbf{N} \rightarrow B$ such that

$$
\lim _{\mathrm{n} \rightarrow \infty}\left\|\mathrm{P} \mathrm{A}_{\mathrm{n}}\right\|_{B}+\left\|\mathrm{A}_{\mathrm{n}} \mathrm{P}\right\|_{B}=0 .
$$

We write \|\| for the norm on $A$ :

$$
\|\mathbf{A}\|=\sup _{\mathbf{n} \in \mathbf{N}}\|\mathbf{A}\|_{B} \quad(\forall \mathbf{A} \in A) .
$$

Let $K$ be the set of all $\mathrm{A} \in A$ such that

$$
\left\{\mathbf{n} \in \mathbf{H}:\left\|\mathbf{P} A_{n}\right\|+\left\|A_{n} P\right\| \neq 0\right\} \text { is finite. }
$$

PROPOSITION. Pedersen's ideal in $A$ is just $K$.

PROOF. That $K$ is an ideal is trivial.

For each $A \in A$ and $n \in \mathbf{M}$, let $A^{(n)}$ be the element of $K$ defined by

$$
A_{m}^{(n)}=A_{m}(\forall m=1,2, \ldots, n), A_{k}^{(n)}=Q_{k} Q \quad(\forall k=n+1, n+2, \ldots) .
$$

Then, for each $\mathrm{A} \in A$,

$$
\begin{aligned}
& \overline{i \text { im }}\left\|\mathrm{A}-\mathrm{A}{ }^{(\mathrm{n})}\right\|=\overline{\mathrm{n}} \sup _{\mathrm{k}>\mathrm{n}}\left\|\mathrm{A}_{\mathrm{k}}-\mathrm{QA}_{\mathrm{k}} \mathrm{Q}\right\|_{B} \leq \\
& \overline{i \mathrm{im}} \sup _{\mathrm{k}>\mathrm{n}}\left\|\mathrm{PA}_{\mathrm{k}} \mathrm{Q}\right\|_{B}+\left\|\mathrm{QA}_{\mathrm{k}} \mathrm{P}\right\|_{B}+\left\|\mathrm{PA}{ }_{\mathrm{k}} \mathrm{P}\right\|_{B}=0
\end{aligned}
$$

by (2.1), which proves that $K$ is dense in $A$.

Since the minimal dense ideal of $A$ contains all positive elements $A \in A$ such that $\mathrm{AB}=\mathrm{A}$ for some $\mathrm{B} \in A^{+}$, it will suffice in showing $K$ is Pedersen's ideal to demonstrate that $K$ is spanned by elements of this sort. Since $K$ is evidently spanned by its positive elements, it will be sufficient to examine an arbitrary positive element $\mathrm{A}$ of $K$. For such $\mathrm{A} \in K^{+}$, there exists $\mathrm{n} \in \mathrm{N}$ such that $\mathrm{PA}_{\mathrm{m}}=0=\mathrm{A}_{\mathrm{m}} \mathrm{P}$ for all $\mathrm{m}>\mathrm{n}$. Let $\mathrm{B} \in \mathrm{A}^{+}$be defined by

$$
B_{k} \equiv \mathrm{I} \quad(\forall \mathrm{k}=1,2, \ldots, \mathrm{n}), \mathrm{B}_{\mathrm{m}} \equiv \mathrm{Q} \quad(\forall \mathrm{m}=\mathrm{n}+1, \mathrm{n}+2, \ldots) .
$$

Then, since $A_{m}=Q A_{m} Q$ for $a 11 m>n, A B=A$. Q.E.D.

Let $\mathrm{F}$ be the bounded linear functional on $A$ defined by

$$
F(A) \equiv \sum_{n=1}^{\infty}<A_{n}\left(b_{1}\right), b_{-1}>\cdot 2^{-n} \quad(\forall A \in A) .
$$

Let $D \in K$ be the partial unitary operator defined by

$$
D_{n} \equiv Q \quad(\forall n \in \mathbf{N}) .
$$


For $\mathrm{G} \in A^{\prime}$ and $\mathrm{A} \in A$, the linear functionals $\mathrm{A} \cdot \mathrm{G}$ and $\mathrm{A} \cdot \mathrm{G} \cdot \mathrm{A}$ are $\operatorname{def}$ ined by

$$
A \cdot G(B) \equiv G(A B) \text { and } A \cdot G \cdot A(B) \equiv G(A B A) \quad(\forall B \in A) \text {. }
$$

Let $S$ be the linear span of the set of all elements of $A^{\prime}$ of the form $A^{*} \cdot G \cdot A$ such that $\mathrm{A} \in K^{+}$and $\mathrm{G} \in A^{\prime}$.

THEOREM. The linear functional $\mathrm{D} \cdot \mathrm{E}$ is not in $S$.

PROOF. Assume false. Then there exists a finite subset $F$ of $K^{+}$and a map $\mathrm{G} \mid F \rightarrow A^{\prime}$ such that

$$
\mathrm{D} \cdot \mathrm{F}=\sum_{\mathrm{A} \in \mathrm{F}} \mathrm{A} * \cdot \mathrm{G}_{\mathrm{A}} \cdot \mathrm{A}
$$

Choose $n \in \mathbb{H}$ such that

$$
\mathrm{PA}_{\mathrm{m}}=\mathrm{A}_{\mathrm{m}} \mathrm{P}=0 \quad(\forall \mathrm{A} \in F ; \mathrm{m}=\mathrm{n}, \mathrm{n}+1, \ldots) .
$$

Let $B \in A$ be defined by

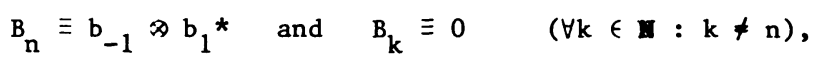

and note that

$$
\mathrm{QB}_{\mathrm{n}}=\mathrm{B}_{\mathrm{n}} \quad \text { and } \quad \mathrm{QB}_{\mathrm{n}} \mathrm{Q}=0
$$

We have

$$
D \cdot F(B)=F(D B)=\left\langle(D B)_{n}\left(b_{1}\right), b_{-1}>2^{-n}=2^{-n} \neq 0 .\right.
$$

For each $A \in F$, we have $A_{n}=Q A_{n} Q$; therefore, since $\left(b_{-1} \otimes b_{1}{ }^{*} Q=0\right.$, it follows that $\mathrm{B}_{\mathrm{n}} \mathrm{A}_{\mathrm{n}}=0$. Thus

$$
\begin{gathered}
B A=0 \quad \text { and } \\
A * \cdot G_{A} \cdot A(B)=G_{A}(A * B A)=0 \quad(\forall A \in F) .
\end{gathered}
$$

But (2.3), (2.4), and (2.5) are incompatible. Q.E.D.

\section{REFERENCE}

[1] Lazar, A. J., and Taylor, D. C., Multipliers of Pedersen's Ideal, Mem. Am. Math. Soc. 169, (1976). 


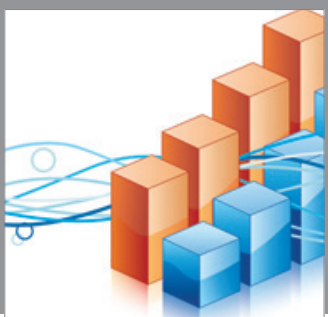

Advances in

Operations Research

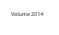

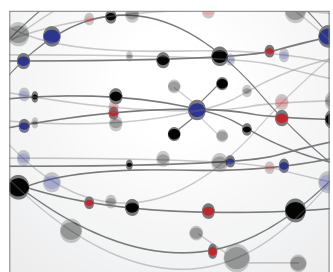

\section{The Scientific} World Journal
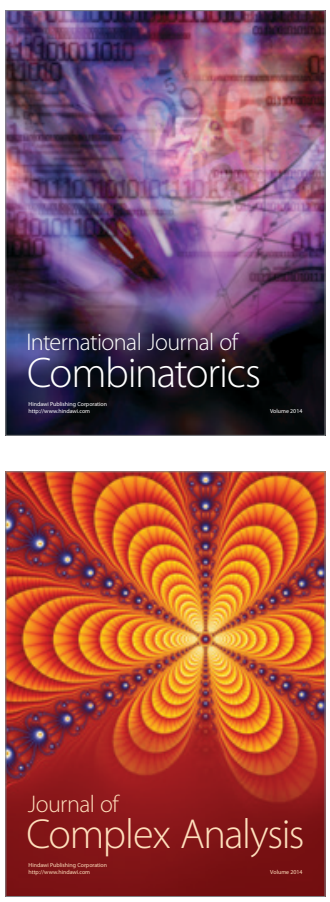

International Journal of

Mathematics and

Mathematical

Sciences
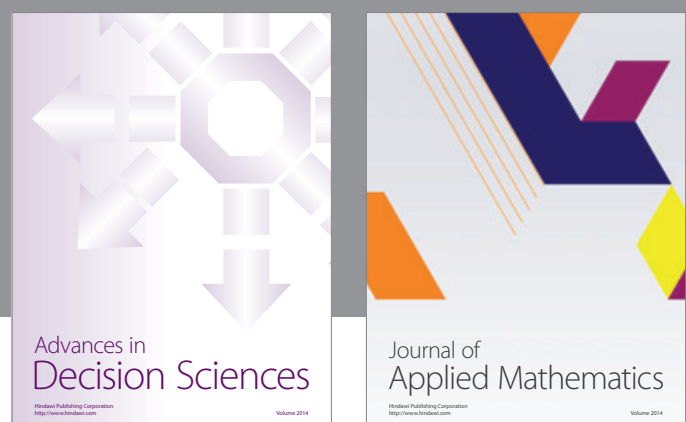

Journal of

Applied Mathematics
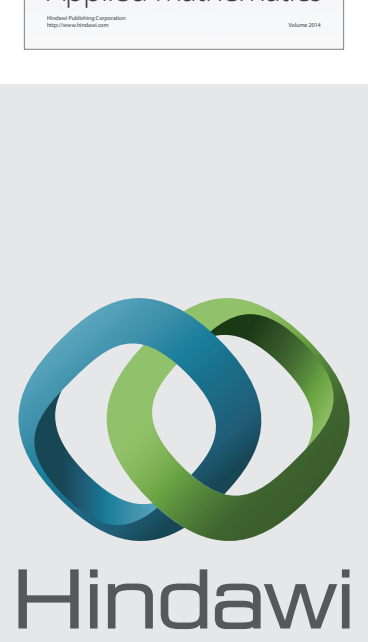

Submit your manuscripts at http://www.hindawi.com
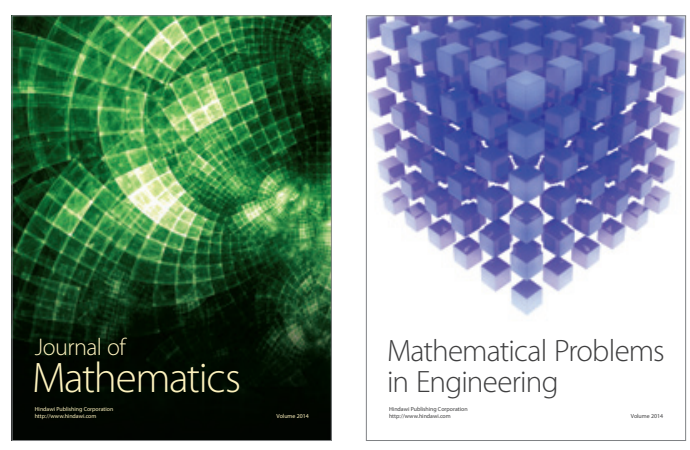

Mathematical Problems in Engineering
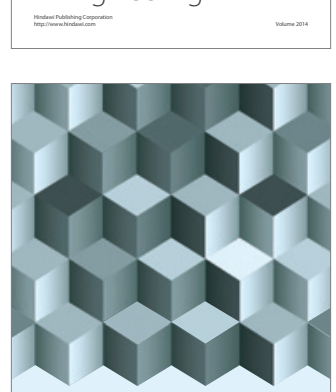

Journal of

Function Spaces
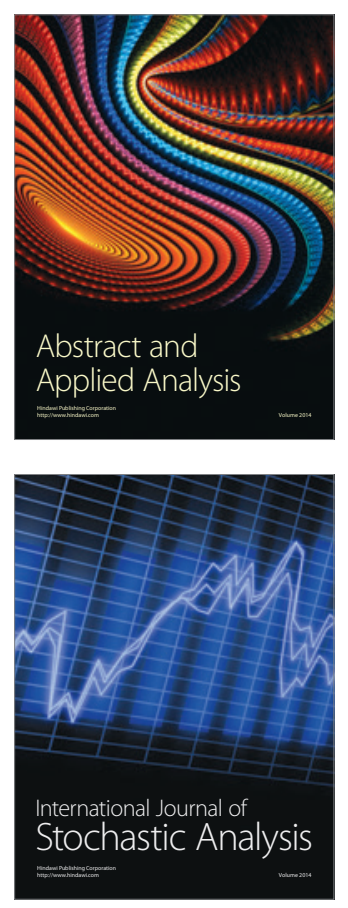

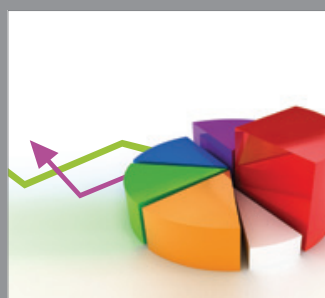

ournal of

Probability and Statistics

Promensencen
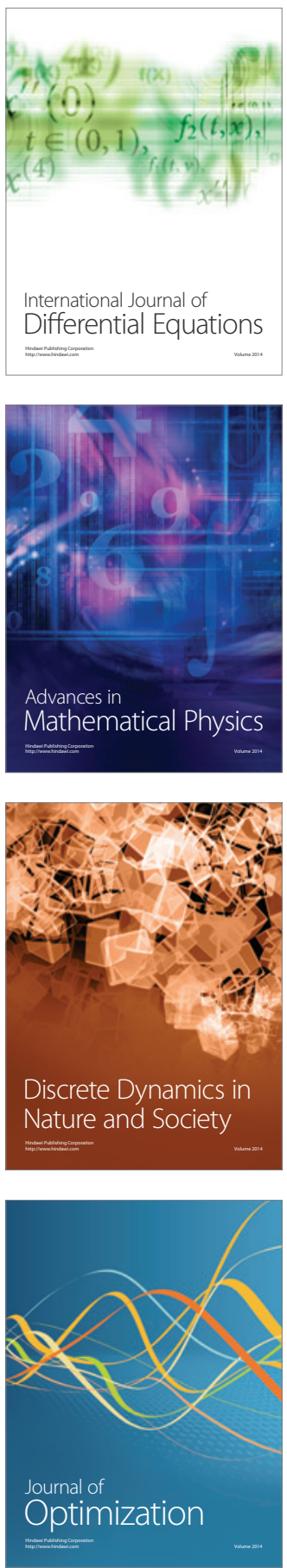